\title{
Rethinking lymph node metastasis and cytoreductive nephrectomy
}

\author{
Michael Leveridge, MD, FRCSC \\ Departments of Urology and Oncology, Queen's University, Kingston, ON, Canada
}

Cite as: Can Urol Assoc J 2016;10(11-12):396-7. http://dx.doi.org/10.5489/cuaj.4252

See related article on page 389 .

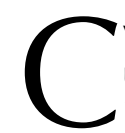
ytoreductive nephrectomy $(\mathrm{CN})$ is a difficult surgery under difficult circumstances. Early studies in the immunotherapy era cemented the survival advantage of $\mathrm{CN}$, though modern prospective data has not yet emerged from the CARMENA and SURTIME trials. ${ }^{1}$ Less certain is the extent to which all regional disease should be resected at the time of $\mathrm{CN}$, that is, whether lymphadenectomy (LND) should feature routinely during surgery. Patel and colleagues have pitched in to address this issue using Surveillance, Epidemiology, and End Results (SEER) registry data in this issue of CUAJ, and found no therapeutic advantage. ${ }^{2}$

The paper covers significant ground while weaving between the metastatic, CN, LND, and node-positive cohorts. Several key findings crystallize. Median survival in newly diagnosed $\mathrm{M} 1$ patients remains less than a year, but has improved over time. $\mathrm{CN}$ is associated with longer survival, selection bias in administrative data notwithstanding. A "true" node dissection (the surrogates here are $\geq 3$ and $\geq 8$ nodes removed) does not impact survival (in fact, any LND was associated with decreased overall and disease-specific survival), and those $\mathrm{CN}$ patients who had nodes removed had worse survival than those with $\mathrm{CN}$ alone. Node-positive patients did much worse that node-negative (8-10 months vs 22 months survival), and the number of positive nodes worsened prognosis further.

These data sit well with other studies in this space, and doubt is cast on the use of LND at the time of CN. Trinh et al also queried SEER for $\mathrm{CN}$ patients and found nodal disease worsened survival, with similar incremental declines with increased node burden. ${ }^{3}$ Mayo Clinic researchers analyzed $305 \mathrm{CN}$ patients, $188(62 \%)$ of whom had a LND. ${ }^{4}$ They found no benefit to LND, even in clinically node-positive patients, and used the cohort alone, as well as propensityscore groupings to find no advantage to LND in cNO patients at high risk for occult node metastasis. The authors advocate against the use of LND at $\mathrm{CN}$, and in fact, double down to suggest that omitting it may afford more minimally invasive $\mathrm{CN}$ (with earlier time to systemic therapy).

It may seem intuitive that once the incision is made, regional disease ought to be resected along with the affected kidney, and it is clear that the best outcomes from $\mathrm{CN}$ are for those patients in whom $\geq 90 \%$ of the disease burden is removed with surgery. ${ }^{5,6}$ It is not clear, however, whether resection of positive nodes contributes to this percentdebulking, or whether the amount of tumour beyond the kidney has already mapped prognosis. Gershman and colleagues note that the pathology of the primary tumour was worse in patients with regional lymphadenopathy, suggesting a different and more aggressive phenotype that allows for lymphatic instead of hematogenous spread. ${ }^{4}$

It should be noted that specific harms have not been identified in those undergoing LND. Certainly the risk of intraoperative grief is higher with the addition of dissection around the great vessels, but the decreased survival in patients in the present study who underwent LND is probably a marker of more aggressive or advanced disease and not of surgical morbidity. The Mayo group looked as well at perioperative morbidity after $\mathrm{CN}$, and found that although LND had hazard ratios (HR) of 1.76 and 1.65 for 30-day complication and increased length of stay (LOS) respectively, neither of these was significant. ${ }^{7}$ Removal of $\geq 13$ nodes was close to significance for prolonging LOS (HR 2.01; $\mathrm{p}=0.06$ ) in their series.

So should surgeons steel themselves to tackle the retroperitoneum in patients undergoing $\mathrm{CN}$ ? It seems clear that clinically node-negative patients don't stand to benefit. Patients with high-volume metastases or those with numerous adverse prognostic factors likely should be spared LND as well (and for many, even CN). ${ }^{8}$ Patients with a large burden of regional node metastases seem unlikely to benefit from an aggressive approach; they have shown poor outcomes in this and other studies and have likely declared themselves as having particularly hostile cancers. ${ }^{2-4,7}$ Navigating the setting of small-volume, easily resectable node metastsis is trickier. There is likely little harm from excising paracaval or para- 
aortic nodes in concert with the hilar dissection, but the benefits are backed by intuition rather than data (in fact, $\mathrm{cN}+$ patients specifically have shown no benefit). ${ }^{4}$ On one side, leaving accessible disease behind feels unpalatable, and some with limited metastatic burden beyond the retroperitoneum may survive far beyond the median; it would seem unfair to leave cancer behind. On the other hand, node involvement betrays adverse biology that may evade any therapeutic efforts, and the data available do not bear out an advantage. Robust prospective data to answer this question is unlikely forthcoming. Patients facing $\mathrm{CN}$ are in peril and we want to do something to help. Studies like this help to resolve where our efforts are best laid and when more isn't actually more.

Competing interests: Dr. Leveridge has been an advisor for Astellas.

\section{References}

1. Flanigan RC, Mickisch G, Sylvester R, et al. Cytoreductive nephrectomy in patients with metastatic rencal cancer: A combined analysis. J Urol 2004; 171:1071-6. http://dx.doi.org/10.1097/01. ju.0000110610.61545.ae
2. Patel HD, Gorin MA, Gupta N, et al. Mortality trends and the impact of lymphadenectomy on survival for renal cell carcinoma patients with distant metastasis. Can Urol Assoc J 2016;10(11-12):389-95. http://dx.doi.org/10.5489/cuaj.1999

3. Trinh QD, Sukumar $S, S c h m i t g e s ~ J$, et al. Effect of nodal metastases on cancer-specific mortality after cytoreductive nephrectomy. Ann Surg Oncol 203; 20:2096-102.

4. Gershman B, Thompson RH, Moreira DM, et al. Lymph node dissection is not associated with improved survival among patients undergoing cytoreductive nephrectomy for metastatic renal cell carcinoma: A propensity score-based analysis. J Urol 2016 Sep 20 epub ahead of print. http://dx.doi.org/10.1016/i. juro.2016.09.074

5. Pierorazio PM, McKiernan JM, McCann TR, et al. Outcome after cytoreductive nephrectomy for metastatic renal cell carcinoma is predicted by fractional percentage of tumour volume removed. BJU Int 2007;100:755-9. http://dx.doi.org/10.1111/j.1464-410X.2007.07108.x

6. Barbastefano J, Garcia JA, Elson P, et al. Association of percentage of tumour burden removed with debulking nephrectomy and progression-free survival in patients with metastatic renal cell carcinoma treated with vascular endothelial growth factor-targeted therapy. BJU Int 2010; 106:1266-9. http:// dx.doi.org/10.1111/i.1464-410X.2010.09323.x

7. Gershman B, Moreira DM, Boorijan SA, et al. Comprehensive characterization of the perioperative morbidity of cytoreductive nephrectomy. Eur Urol 2016;69:84-9. http://dx.doi.org/10.1016/i. eururo.2015.05.022

8. Heng DY, Wells JC, Rini Bl. Cytoreductive nephrectomy in patients with synchronous metastases from renal cell carcinoma: Results from the International Metastatic Renal Cell Carcinoma Database Consortium. Eur Urol 2014;66:704-10. http://dx.doi.org/10.1016/i.eururo.2014.05.034

Correspondence: Dr. Michael Leveridge, Departments of Urology and Oncology, Queen's University, Kingston, ON, Canada; leveridm@kgh.kari.net; twitter: @_TheUrologist_

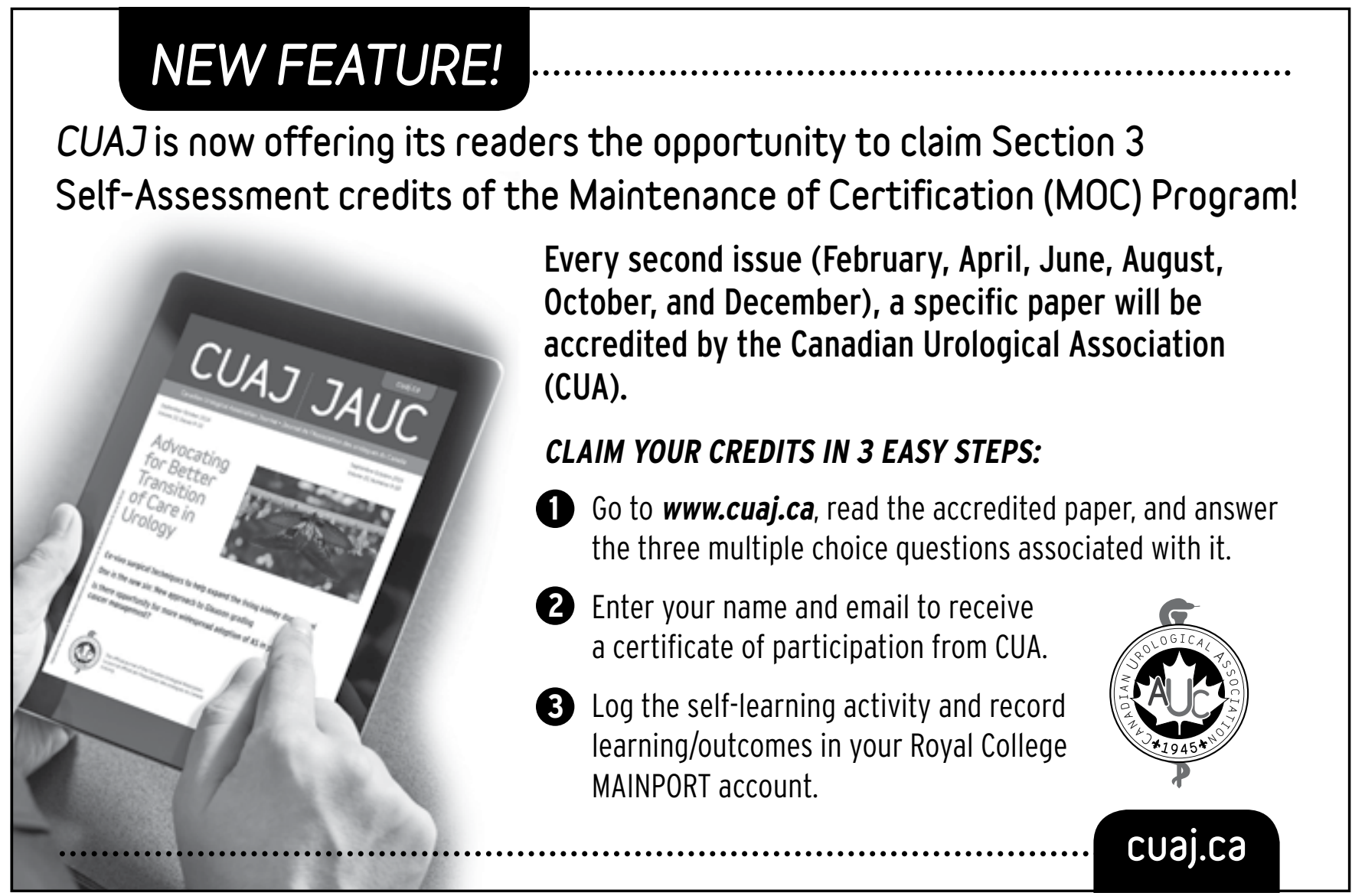

